\title{
Adaptation related to cytokines in man: effects of regular swimming in ice-cold water
}

\author{
B. Dugué and E. Leppänen
}

Minerva Foundation, Institute for Medical Research, Tukholmankatu 2, 00250 Helsinki, Finland

Received 29 June 1999; accepted 11 October 1999

Correspondence: Dr Benoit Dugué, Minerva Foundation, Institute for Medical Research, Tukholmankatu 2, 00250 Helsinki, Finland

\section{Summary}

The cytokine response after thermal stress (sauna + swimming in ice-cold water) was investigated in subjectively healthy persons. Two groups were studied at the end of the winter season: habitual and inexperienced winter swimmers. Blood was collected at rest, after a sauna bath and after a short swim in ice-cold water. Conventional methods and ELISA kits were used to determined the blood picture, serum cortisol and dehydroepiandrosterone sulphate, plasma antidiuretic hormone $(\mathrm{ADH})$ levels, and the levels of several cytokines in plasma and in the supernatants of blood cell cultures which were stimulated with lipopolysaccharide (LPS). In regular winter swimmers, the concentrations of plasma interleukin 6 (IL-6), leukocytes, and monocytes at rest were significantly higher than in inexperienced subjects. In experienced female winter swimmers, the plasma concentration of the soluble receptor for IL-6 was significantly lower than in inexperienced female swimmers. In both groups, granulocytosis, haemoconcentration and significant increases in the concentrations of $\mathrm{ADH}$, cortisol and IL-6 were observed after the stimuli. However, the changes in the cortisol concentration were dramatically larger in habitual winter swimmers. A significant correlation was found between the delta values of cortisol and the basal concentrations of IL-6. In cell cultures, the LPS-induced release of IL-1 $\beta$ and IL-6 was higher at rest in the inexperienced winter swimmers. This release was dramatically suppressed after exposure to the stimuli in the inexperienced winter swimmers but tended to increase in the regular winter swimmers. These stresses appear to challenge both the neuro-endocrine and the immune systems and the results indicate that adaptive mechanisms occur in habitual winter swimmers.

Keywords: adaptive mechanism, ADH, blood picture, cortisol, interleukins, sauna, stress, winter swimming.

\section{Introduction}

Functional bi-directional communication exists between the endocrine and immune systems, and cytokines play a major role in these interactions. The cytokines are able to modulate the hypothalamic-pituitaryadrenocortical axis response in the hypothalamus, the pituitary gland and the adrenals. More than 30 different types of hormonal receptors have been demonstrated on lymphoid and accessory cells. In addition, immunocompetent cells secrete numerous hormones (Gaillard, 1994). The endocrine and immune systems seem to be so intimately linked with each other that they could be regarded as a single network rather than separate systems (Connor \& Leonard, 1998). During exposure to stress (physical, psychological, chronic, acute), these systems (or networks) are challenged. However, information about mechanisms of adaptation to repeated physically stressful conditions in man is lacking. Most of the results of experiments in exercise/sport physiology have indicated a harmful effect of intensive physical training. 
In Finland, swimming in ice-cold water is a fairly common sport or habit. The winter swimmers usually combine it with a hot sauna bath (Kauppinen \& Urponen, 1988; Kauppinen et al., 1989). From a physiological point of view, strong changes in environmental temperature $\left(\right.$ almost $100^{\circ} \mathrm{C}$ ) on a regular basis represents an obvious neuro-endocrine/cardiovascular stress which may lead to adaptive phenomena. Accordingly, this study was undertaken to investigate how thermal stress (sauna + swimming in ice-cold water) affects the endocrine and immune systems in two groups of subjectively healthy persons: habitual winter swimmers (HWS) and non-habitual winter swimmers (NHWS). We were especially interested in the pattern of cytokine and stress hormone responses after such stimuli. A preliminary report has been presented (Dugué et al., 1998).

\section{Subjects and methods}

\section{Subjects}

All specimens were taken from subjectively healthy persons who had given written informed consent to participate in the study. All reported the absence of chronic illness and no use of any medication (other than oral contraceptives) during the week before the experiment. They were 11 females (age 25-52 years, mean 38.7 years) and nine males (age 19-64 years, mean 44.0 years). Among them, five females and seven males were regular winter swimmers who practised this activity more than once a week during the winter. The average number of years of activity was $7 \cdot 5$ (range $1-15$ years). The NHWS did not have any experience of winter swimming during the previous year. It should be pointed out that it was fairly difficult to recruit the NHWS.

\section{Design of the experiment and specimen collection}

The experiments took place during late afternoon in and near a sauna situated $50 \mathrm{~m}$ from a lake as recently described (Dugué et al., 1999). The volunteers sat naked for $15 \mathrm{~min}$ in a sauna heated to $95^{\circ} \mathrm{C}$ with a relative humidity of $30-50 \%$. Then they were subjected to cold air for about $1 \mathrm{~min}$ at a temperature between -15 and $-5^{\circ} \mathrm{C}$ (this experiment was organized on four different occasions during late winter as it was not possible to monitor more than six individuals per session) while walking to the lake, followed by a $0.5 \mathrm{~min}$ swim in ice-cold water, and again a $1 \mathrm{~min}$ walk at the outdoor temperature when returning to the sauna building. This sequence of events is typical for winter swimming. Three blood specimen collections were organized in a small room at the sauna building, one at rest before the sauna bath after a period of $15 \mathrm{~min}$ of sitting according to the Scandinavian recommendation on specimen collection (Alström et al., 1993), a second collection directly after the sauna bath (the volunteers were not allowed showering/cooling options), and the last one after exposure to both cold air and water. Blood was collected from the cubital vein using minimum tourniquet, Venoject ${ }^{\circledR}$ needles and evacuated bloodcollecting tubes for serum, EDTA-plasma and sterile adenine-citrate-dextrose (ACD)-plasma (Terumo Co.) and a Vacutainer CPT $^{\mathrm{TM}}$ for cell separation (Becton Dick- inson). Blood for cytokine determination in plasma was collected in ice-chilled tubes and kept on ice until further processing. This study was approved by the ethical committee of our institute.

\section{Isolation and stimulation of peripheral blood mononuclear cells}

Venous blood was collected in tubes containing a sodium citrate gel and a density gradient medium (Vacutainer CPT ${ }^{\mathrm{TM}}$ for cell separation, Becton Dickinson). Specimens were then centrifuged at $1500 \mathrm{~g}$ for $20 \mathrm{~min}$ and the buffy coats transferred to sterile tubes, then washed twice with sterile phosphate buffer, and seeded at a concentration of $2 \times 10^{6}$ cells $/ \mathrm{ml}$ in RPMI-1640 culture medium (Biological Industries) supplemented with $2 \mathrm{mmol} \mathrm{l}^{-1}$ glutamine, $100 \mathrm{U} \mathrm{ml}^{-1}$ penicillin, $100 \mathrm{mg} \mathrm{ml}^{-1}$ streptomycin and $10 \%$ heatinactivated calf serum with or without lipopolysaccharide (LPS, E. coli 0111:B4, Sigma; at $1 \mathrm{ng} \mathrm{ml}^{-1}$ ) at $37^{\circ} \mathrm{C}$ for $14 \mathrm{~h}$ in a humidified $5 \% \mathrm{CO}_{2}$ atmosphere. Supernatants were aspirated, freed of cells by centrifugation, and stored frozen at $-20^{\circ} \mathrm{C}$ until analysis.

\section{Stimulation of whole-blood culture}

Specimens were collected in sterile ACD tubes (Terumo) and cultivated in dishes for cell culture (Costar) in the presence of $100 \mathrm{U} \mathrm{ml}^{-1}$ penicillin, 
$100 \mu \mathrm{g} / \mathrm{ml}$ streptomycin with or without LPS $\left(10 \mathrm{ng} \mathrm{ml}^{-1}\right)$ at $37^{\circ} \mathrm{C}$ for $14 \mathrm{~h}$ in a humidified $5 \%$ $\mathrm{CO}_{2}$ atmosphere. Samples were aspirated, centrifuged $(800 \mathrm{~g}$ for $15 \mathrm{~min})$, and the supernatants stored frozen at $-20^{\circ} \mathrm{C}$ until analysis.

\section{Blood picture and differential counts}

Blood smears were drawn immediately after the specimen collection. The cell population was estimated after May-Grünwald-Giemsa coloration. The specimens for the blood picture determination were stored overnight at $4{ }^{\circ} \mathrm{C}$ and analysed the following morning in a Sysmex-1000 machine at the clinical reference laboratory of Medix-Diacor Co, Espoo, Finland. The following data were recorded: leukocyte, erythrocyte and platelet counts, haemoglobin concentration, haematocrit, mean cell volume $(\mathrm{MCV})$, mean cell haemoglobin $(\mathrm{MCH})$, mean corpuscular haemoglobin concentration (MCHC) and platelet concentration.

\section{Cortisol, ADH, DHEA-SO 4 and cytokine measurements}

ELISA kits for determination of cortisol were purchased from Orion Diagnostica; for the dehydroepiandrosterone sulphate (DHEA-SO $\mathrm{S}_{4}$ ) and prolactin, the kits was purchased from Diagnostic Products Corporation, and for IL-1 $\beta$, IL-1Ra, IL- 6 and its receptor the kits were purchased from $\mathrm{R} \& \mathrm{D}$ Systems Europe. Anti-diuretic hormone (ADH) was analysed with a radioimmunoassay developed at our institute (Fyhrquist et al., 1976). All the samples were analysed in the same series. The intra-assay variations were $5 \cdot 0$ and $3 \cdot 1 \%$ for cortisol concentrations of $72 \cdot 0$ and $1241 \mathrm{nmol} \mathrm{l}^{-1}$, respectively; $<5 \cdot 0 \%$ for prolactin concentrations of $5 \cdot 0$ and $100 \mu \mathrm{g} 1^{-1} ; 6.9$ and $6.4 \%$ for IL- $1 \beta$ concentrations of 1.5 and $4.6 \mathrm{ng} \mathrm{l}^{-1} ; 6 \cdot 2$ and $5 \cdot 3 \%$ for IL-1Ra concentrations of 150 and $880 \mathrm{ng}$ $\mathrm{I}^{-1} ; 11.4$ and $5.9 \%$ for IL- 6 concentrations of 0.36 and $2.73 \mathrm{ng} \mathrm{l}^{-1} ; 8.6$ and $2.6 \%$ for IL-6 receptor concentrations of 134 and $644 \mathrm{ng} \mathrm{l}^{-1} ; 10.5$ and $11.5 \%$ for $\mathrm{ADH}$ concentrations of $2 \cdot 8$ and $11.5 \mathrm{ng} \mathrm{l}^{-1}$; and $7 \cdot 2$ and $6.0 \%$ for DHEA-SO $\mathrm{D}_{4}$ concentrations of 43 and $568 \mu \mathrm{g} \mathrm{dl}^{-1}$. The detection limits for the determination of IL-1 $\beta$, IL-1Ra, IL- 6 and IL-6sR were $0 \cdot 1,14$, $0 \cdot 08$ and $140 \mathrm{ng} \cdot \mathrm{e}^{-1}$, respectively.
Table 1 Blood picture and blood components before and after thermal stress (sauna + swimming in ice-cold water) in all of our participants.

\begin{tabular}{|c|c|c|}
\hline \multirow[b]{2}{*}{ Analytes } & \multicolumn{2}{|c|}{ Mean value (range) } \\
\hline & Before & After \\
\hline Leukocytes $\left(10^{9} / \mathrm{l}\right)$ & $6 \cdot 6(4 \cdot 8-9 \cdot 2)$ & $7 \cdot 7(5 \cdot 1-11 \cdot 0)^{\star \star \star}$ \\
\hline Neutrophils $\left(10^{9} \mathrm{I}^{-1}\right)$ & $3.69(1.99-5.29)$ & $4.01(1.91-5.78)^{*}$ \\
\hline Lymphocytes $\left(10^{9} \mathrm{I}^{-1}\right)$ & $2 \cdot 26(1.48-3.37)$ & $3.00(1.86-4.82)^{\star \star *}$ \\
\hline Monocytes $\left(10^{9} \mathrm{I}^{-1}\right)$ & $0.42(0.06-0.78)$ & $0.49(0.05-0.94)$ \\
\hline Eosinophils $\left(10^{9} \mathrm{I}^{-1}\right)$ & $0.22(0.00-0.51)$ & $0.22(0.0-0.77)$ \\
\hline Erythrocytes $\left(10^{12} \mathrm{I}^{-1}\right)$ & $4.5(4 \cdot 0-5 \cdot 4)$ & $4 \cdot 7(4 \cdot 2-5 \cdot 5)^{\star \star \star}$ \\
\hline Haemoglobin $\left(\mathrm{g} \mathrm{I}^{-1}\right)$ & $137(119-159)$ & $144(126-164)^{\star * *}$ \\
\hline Haematocrit (vol. fraction) & $40(34-45)$ & $42(36-47)^{\star \star \star}$ \\
\hline $\mathrm{MCH}(\mathrm{pg})$ & $31(29-33)$ & $31(29-33)$ \\
\hline Cortisol (nmol I-1) & $292(130-480)$ & $471(148-805)^{\star \star *}$ \\
\hline $\mathrm{DHEA}^{-\mathrm{SO}_{4}}\left(\mathrm{mg} \mathrm{l}^{-1}\right)$ & $2 \cdot 3(0 \cdot 9-5 \cdot 1)$ & $2 \cdot 4(1 \cdot 0-5 \cdot 1)$ \\
\hline $\mathrm{ADH}\left(\mathrm{ng} \mathrm{I}^{-1}\right)$ & $7.94(2 \cdot 54-14 \cdot 3)$ & $9 \cdot 8(5 \cdot 6-16 \cdot 2)^{\star \star}$ \\
\hline Prolactin $\left(\mathrm{ng} \mathrm{I}^{-1}\right)$ & $10 \cdot 5(2 \cdot 5-44 \cdot 0)$ & $18.9(4 \cdot 0-44 \cdot 2)^{\star *}$ \\
\hline $\mathrm{IL}-1 \beta\left(\mathrm{ng} \mathrm{I^{-1 }}\right)$ & $0.74(N D-8.5)$ & $0.68(N D-7.5)$ \\
\hline IL-1Ra (ng I $\left.{ }^{-1}\right)$ & $198(100-480)$ & $189(105-255)$ \\
\hline IL-6 $\left(\mathrm{ng} \mathrm{I}^{-1}\right)$ & $1.51(0.55-3.2)$ & $1.89(0.72-4.4)^{\star \star *}$ \\
\hline $\mathrm{IL}-6 \mathrm{sR}\left(\mu \mathrm{g} \mathrm{\textrm {I } ^ { - 1 } )}\right.$ & $30(20-38)$ & $31(21-39)^{\star}$ \\
\hline
\end{tabular}

Abbreviations: $\mathrm{MCH}$, mean corpuscular haemoglobin; IL, interleukin; $\mathrm{sR}$, soluble receptor; $\mathrm{Ra}$, receptor antagonist; $\mathrm{ADH}$, anti-diuretic hormone; ND, non-detectable; ${ }^{*} P<0.05 ;{ }^{\star \star} P<0.01 ;{ }^{\star \star \star} P<0.001$ compared to the basal level.

\section{Data processing and statistical analysis}

The data were analysed using non-parametric statistical methods: Wilcoxon signed rank test for paired data and Mann-Whitney test for group comparison. The Friedman test was used to compare three groups. However, the interactions of different factors (i.e. age, gender, training) were studied using two-factor repeated-measures ANOVA.

\section{Results}

The changes in the concentrations of haematological analytes, pro-inflammatory cytokines and stress hormones are summarized in Tables 1 and 2 .

At rest, the plasma IL-6-values observed in habitual winter swimmers (HWS) were significantly higher than the concentrations seen in the inexperienced winter swimmers (mean HWS $1.7 \mathrm{ng} \mathrm{l}^{-1}$, SD 0.6, $n=12$ versus mean NHWS $1 \cdot 0 \mathrm{ng}^{-1}$, SD $0 \cdot 5, n=8$; $P<0 \cdot 05)$. In females HWS, plasma IL-6sR was significantly lower (mean $7 \mu \mathrm{g} \mathrm{l} \mathrm{l}^{-1}$, SD $4, n=5$ ) than in female NHWS (mean $34 \mu \mathrm{gl}^{-1}$, SD $4, n=6$; 
Table 2 Concentrations of serum and plasma components in the thermal test, values of habitual winter swimmers (HWS) and non habitual winter swimmers (NHWS) calculated separately.

\begin{tabular}{|c|c|c|c|c|c|c|}
\hline \multirow[b]{2}{*}{ Analyte } & \multirow[b]{2}{*}{ Group } & \multicolumn{3}{|c|}{ Results $^{a}$} & \multicolumn{2}{|c|}{ Statistical analysis $^{b}$} \\
\hline & & Basal level (1) & After sauna (2) & After cold stress ( 3 ) & At rest $(P<)^{c}$ & Delta values $(P<)$ \\
\hline \multirow{3}{*}{$\begin{array}{l}\text { Monocyte total count } \\
\left(10^{9} \text { cells }\left.\right|^{-1}\right)\end{array}$} & HWS & $0.48(0.20-0.78)$ & $0.40(0.17-0.80)$ & $0.44(0.05-0.80)$ & 0.05 & 0.08 for ' 2 ' versus ' 1 ' \\
\hline & & & & & & 0.007 for ' 3 ' versus ' 1 ' \\
\hline & NHWS & $0.32(0.06-0.54)$ & $0.45(0.15-1.01)$ & $0.58(0.32-0.93)$ & & 0.35 for ' 3 ' versus ' 2 ' \\
\hline \multirow[t]{2}{*}{ Cortisol (nmol I-1) } & HWS & 296 (130-480) & $459(145-800)$ & 544 (148-805) & 0.78 & $\begin{array}{l}0.009 \text { for ' } 2 \text { ' versus ' } 1 \text { ' } \\
0.03 \text { for ' } 3 \text { ' versus ' } 1 \text { ' }\end{array}$ \\
\hline & NHWS & $285(185-480)$ & $258(175-400)$ & $359(190-570)$ & & 0.56 for ' 3 ' versus ' 2 ' \\
\hline
\end{tabular}

${ }^{a}$ Mean values (extreme values); ${ }^{b}$ Mann-Whitney test; ${ }^{\circ} H W S$ versus NHWS.

$P<0.03)$. Leukocyte counts were higher in female HWS (mean $7 \cdot 9 \times 10^{9}$ cells $^{-1}$, SD $0 \cdot 8, n=5$ ) than in female NHWS (mean $6.3 \times 10^{9}$ cells $^{-1}$, SD $0 \cdot 9$, $n=6 ; P<0.05)$. The same applies to total monocyte counts (mean HWS for the whole group $0.48 \times$ $10^{9}$ cells $^{-1}$, SD $0 \cdot 18, n=12$ versus mean NHWS $0.32 \times 10^{9}$ cells $^{-1}$, SD $\left.0.16, n=8 ; \quad P<0 \cdot 05\right)$ and neutrophil counts (mean female HWS $4.53 \times$ $10^{9}$ cells $1^{-1}$, SD $0 \cdot 50, n=5$ versus mean female NHWS $3.64 \times 10^{9}$ cells $^{-1}$, SD 0.44, $\left.n=6 ; P<0 \cdot 05\right)$.

After the thermal stress (sauna + swimming in icecold water), the total leukocyte $(P<0 \cdot 001)$, neutrophil $(P<0 \cdot 05)$, lymphocyte $(P<0 \cdot 001)$ and erythrocyte counts $(P<0 \cdot 001)$, the haemoglobin concentration $(P<0.001)$ and the haematocrit values $(P<0 \cdot 001)$ were significantly higher than in the controls. The concentrations of IL-6 $(P<0 \cdot 001)$ and its receptor $(P<0.05)$, prolactin $(P<0.01)$ and $\mathrm{ADH} \quad(P<0.01)$ increased significantly after the stress, whereas the concentrations of IL- $1 \beta$, IL-1Ra, DHEA-SO ${ }_{4}$, and the $\mathrm{MCV}, \mathrm{MCH}, \mathrm{MCHC}$ values and platelet counts did not change significantly. When the results were corrected for haemoconcentration (according to the changes in the haematocrit values), the pattern of the changes was rather similar.

Interestingly, habitual winter swimming significantly influenced the changes in the monocyte counts $(P<0.004)$ and the cortisol concentration $(P<0 \cdot 05)$. For these analytes, we also report the results obtained from specimens collected after the sauna session (Table 2). After these stimuli, the number of monocytes dropped in the HWS $(P<0 \cdot 05)$ whereas it rose in NHWS $(P<0.02)$. The concentration of cortisol rose after the sauna in HWS $(P<0 \cdot 01)$ whereas a significant increase was seen in NHWS only after swimming in ice-cold water $(P<0 \cdot 05)$. When the results were corrected for haemoconcentration, a significant decrease was obtained for the NHWS after the sauna session $(P<0 \cdot 05)$. We also observed a significant and positive correlation between the changes in the concentration of cortisol after sauna and the level of plasma IL-6 at rest $(r=0.48, n=20, P<0.036)$ (Fig. 1).

In LPS-stimulated cultures, large amounts of IL-1 $\beta$ and IL-6 are produced (Table 3). To facilitate comparisons, the data were expressed as amount of cytokine produced per monocyte. The data obtained for IL-1 $\beta$ and IL-6 with the whole-blood cultures correlated well with the data obtained with the cultures of isolated peripheral blood mononuclear cells $(P<0.05$ in all cases). The basal LPS-induced releases of IL-1 $\beta$ and IL- 6 were significantly higher in

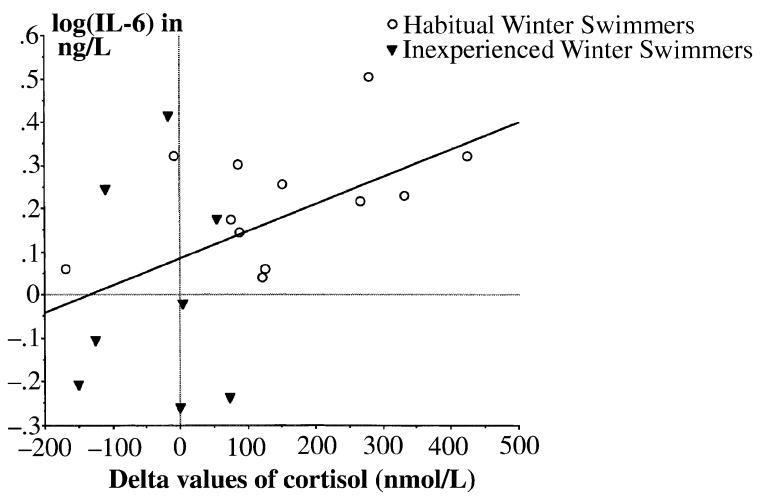

Figure 1 Correlation between the changes in cortisol and the basal concentration of interleukin-6. The delta values of cortisol (expressed in nmol $\mathrm{l}^{-1}$ ) are the differences between the results obtained after the sauna session and those at rest. This correlation was found to be significant. 


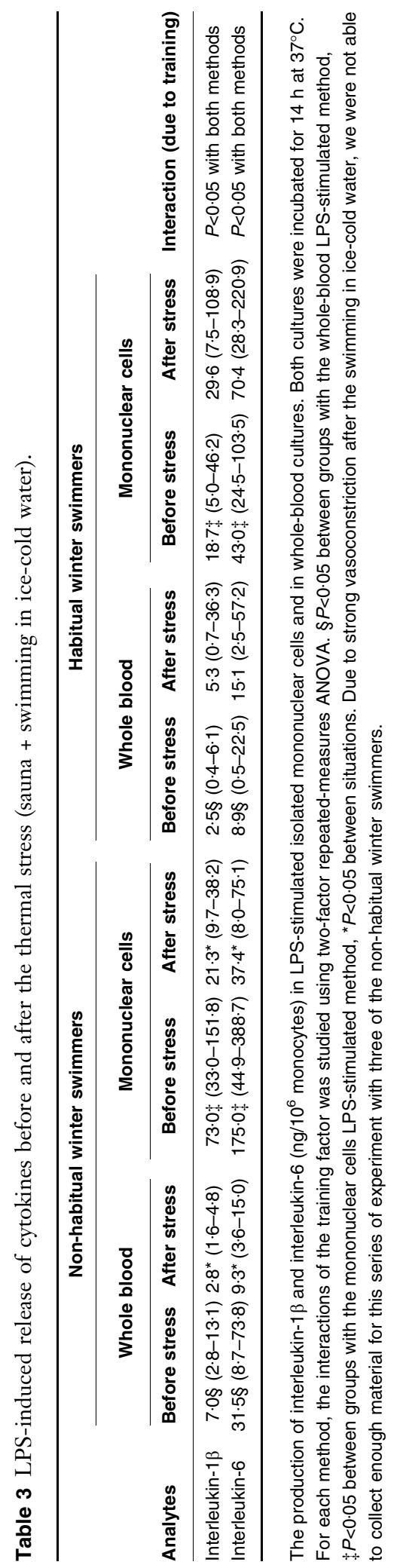

the NHWS than in the HWS $(P<0 \cdot 05)$. Moreover, the NHWS showed a decrease in their capacity for producing IL- $1 \beta$ and IL- 6 after the stimuli, whereas the HWS had their production slightly stimulated.

\section{Discussion}

Winter swimming is a form of self-care practice. It consists of taking a short swim in ice-cold water regularly throughout the winter season. Winter swimmers in Finland usually combine it with a hot sauna. Those practising it often strongly believe that regular swimming/bathing in ice-cold water is wholesome and that they fall ill less often than others. However, there are no well-controlled data to support this claim. Adaptation to repeated hot and cold stress has been postulated as a mechanism resulting in increased resistance to stress and diseases, but again little evidence exists. Surprisingly, there are only limited data available on the processes occurring during cold adaptation (e.g. Jansky et al., 1996).

Interestingly, we observed that at rest the concentrations of plasma IL-6, leukocytes and monocytes in regular winter swimmers are higher than in inexperienced winter swimmers. After taking a harsh sauna bath and a short swim in ice-cold water, the changes in the heart rate and blood pressure were similar to those previously reported (i.e. increase in heart rate and decrease in the diastolic blood pressure after the sauna bath, increase in systolic blood pressure after the sauna bath and the cold stress) (KukkonenHarjula et al., 1989; Zenner et al., 1980). Granulocytosis, haemoconcentration (probably due to sweating in the sauna) and a significant increase in the plasma concentrations of IL-6 and ADH occurred after these stressful stimuli. Similar findings have recently been reported in seven volunteers who first remained seated for $1 \mathrm{~h}$ in a water bath at 35 or $38^{\circ} \mathrm{C}$ and then for $2 \mathrm{~h}$ in a climatic chamber maintained at $5^{\circ} \mathrm{C}$ (Brenner et al., 1999). Interestingly, when studying the monocyte counts and the concentration of cortisol, we found a significant interaction of the changes, which were probably due to training. The monocyte count decreased after the sauna bath in HWS whereas it increased in NHWS. After the cold stress, the monocyte counts continued to rise in the NHWS and remained stable in HWS. The changes in the cortisol concentration were dramatically 
greater in HWS than in NHWS after the stimuli. However, plasma cortisol decreased after the sauna in NHWS whereas it significantly increased in HWS. In both groups, after the ice-cold stress, the cortisol concentration was significantly higher than at rest. These observations can be explained in terms of adaptation. Recently, it has become clear that the release of cortisol in blood mainly happens after and not during the 15 min sauna exposure (Dugué et al., 1996a; Jezova et al., 1994; Kukkonen-Harjula et al., 1989) and that during this period the catabolism of cortisol may be increased (Jezova et al., 1994). This could explain the decrease in cortisol we observed in the NHWS. However, the secretory capacity of the adrenals of individuals who practise sport are enhanced (Kjaer, 1998). It could be hypothesized that the same happens in the cortisol synthesis/secretory system of regular winter swimmers, who did show an increase in plasma cortisol directly after sauna.

The increase in the concentrations of cortisol, $\mathrm{ADH}$ and prolactin show that the stimuli are able to activate the hypothalamic-pituitary-adrenal axis. It is known that IL-6 is a mediator of the interaction of the immune system with the hypothalamic-pituitaryadrenal axis, and it has recently been postulated that IL-6 may be a long-term regulator of the adrenal stress response (Päth et al., 1997; Salas et al., 1990). It has also recently been demonstrated that IL-6 stimulates the cortisol secretion from adult human adrenocortical cells (Weber et al., 1997). Moreover, it has been shown that depressed patients have higher plasma concentrations of IL-6 and cortisol (Dinan, 1994; Maes et al., 1997). The significant correlation we observed between the delta values of cortisol and the basal concentrations of IL-6 also suggests a chronic in vivo effect of IL-6 on the cortisol response.

We faced a methodological problem when investigating LPS-induced release of cytokines from blood cells. Nowadays, a number of authors prefer to study cytokine-stimulated release using cultures of whole blood rather than isolated peripheral blood mononuclear cells. Experiments with isolated cells have drawbacks, because the cells are removed from their physiological environment and artefacts may occur due to activation of the cells during their isolation (Dugué et al., 1996b). However, whole-blood cultures entail some inconveniences (Nerad et al., 1992). There are indications that the LPS-induced release of IL-1 $\beta$ and IL-6 is inhibited by cortisol (Arzt et al., 1994; Rock et al., 1992; Sauer et al., 1996; Waage et al., 1990). However, the whole-blood technique has been validated on specimens obtained from persons at rest. Therefore, we decided to investigate the LPSinduced release of cytokines using both methods. In these experiments, we used the lowest LPS concentration able to induce the production of cytokines by blood cells (i.e. $1 \mathrm{ng} \mathrm{m}^{-1}$ for the peripheral blood mononuclear cell culture and $10 \mathrm{ng} \mathrm{ml}^{-1}$ for the whole-blood culture (Nerad et al., 1992)). Both techniques gave similar results for IL-1 $\beta$ and IL-6. Significant interaction due to previous training was observed when comparing the basal levels of the LPSinduced production of IL-1 $\beta$ and IL- 6 and also the changes of LPS-stimulated release of these cytokines. The basal level of the LPS-induced release of IL-1 $\beta$ and IL-6 was significantly higher in the NHWS compared to the HWS. Moreover, the LPS-induced release of IL-1 $\beta$ and IL-6 was significantly suppressed after exposure to the stimuli in the NHWS but tended to increase in the HWS.

Some authors have reported that immune function was increased by light or moderate exercise but decreased by excessive physical work. Kvernmo et al. (1992) observed a significant decrease in LPS-induced TNF production in highly trained athletes at rest compared to sedentary controls. The same may have applied to our subjects in the case of LPS-induced release of IL-6 and IL-1 $\beta$. Moreover, the same authors observed a decreased LPS-induced TNF production following exercise (Kvernmo et al., 1992). In the present study, we were also able to find a decrease in the LPS-induced release of cytokines but only in the NHWS. It is believed that exercise is followed by transient immunosuppression which is due to the release of glucocorticoids. Although the concentration of cortisol is dramatically increased in the HWS after the stress (even more than in the NHWS), the LPS-induced release of cytokines is not decreased and even tends to increase. This may be due to changes in the corticosteroid sensitivity of peripheral blood mononuclear cells (e.g. down-regulation of glucocorticoid receptors, changes in the affinities of these receptors). However, the changes in the concentration of blood cells after thermal stress may also be due to redistribution of cells. Redistributed cells may have different abilities to produce cytokines. 
It is believed that stress suppresses immune function and increases susceptibility to infections and diseases, and impairs wound healing, etc. It seems paradoxical that an organism would suppress its immune system at a time when it is likely to need an active immune response. For instance, under conditions of stress, it may be injured or infected by a stressor agent such as an attacker (Sapolsky, 1993). However, stress is also thought to exacerbate inflammatory diseases such as psoriasis, asthma and arthritis (which may be ameliorated by suppression of the immune system) (Dhabhar \& McEven, 1997). Also, stress is not a stringent concept - it is used as a term for various immune phenomena and other conditions (Dugué et al., 1992, 1993). As stated, our winter swimmers believed that regular ice-cold baths are wholesome and make them resistant to diseases. However, is the immune response involved? The basal levels of several analytes (leukocytes, monocytes, IL-6) involved in the immune response are higher than in controls, indicating that the immune system is slightly stimulated, leading to speculation that they are more prepared to react to an infection. However, in the same persons, some other immune aspects are impaired e.g. the mononuclear cells released a lower amount of IL- $1 \beta$ and IL- 6 . This could be interpreted as a counter-action breaking the development of an inflammatory process.

However, it should also be taken into account that it may be difficult to interpret our in vivo and in vitro results together, especially in the case of IL-6. In blood, the major IL-6-producing cell line is thought to be the monocytes, as the other cells (e.g. B and T cells and granulocytes) have been shown to produce only little (De Rijk et al., 1996). However, in the circulation, IL-6 may also be derived from other sources such as endothelial cells (De Rijk et al., 1997). Moreover, the results obtained after stimulation of the cells indicate their degree of priming to produce cytokines. They do not indicate the amount of cytokine that the cells are currently producing.

This study provides new information on the responses to hot and cold temperature and on the possible adaptation that subjects may develop if they experience such stress regularly. We showed that the neuroendocrine and immune systems are challenged after thermal stress. Moreover, at rest, the blood concentrations of several analytes involved in the immune system were significantly enhanced in the HWS. An adaptation to repeated hot and cold stress has previously been postulated as a mechanism for body sturdiness, resulting in an increased tolerance to stress and diseases. Exposure to repeated intensive shortterm cold stimuli is often applied in hydrotherapy/ physiotherapy to promote strength. Our results could contribute to the explanation of such phenomena.

\section{Acknowledgements}

This research was supported by the Signe and Ane Gyllenberg, the Ella and Georg Ehrnrooth, the Magnus Ehrnrooth, the Oskar Öflund and the Yrjö Jahnsson Foundations. The kind and excellent technical help of Arja Haapalinna, Liisa Haapalinna, Jaana Friman and Vesa Yli-Pelkonen is greatly acknowledged. The authors express their sincere thanks to the volunteers who participated in this study and the City of Vantaa for allowing us to use their facilities at Lake Kuusijärvi, and to Professor Ralph Gräsbeck, the head of the biochemistry group at the Minerva Institute, for criticism in preparing the manuscript.

\section{References}

AlströM T., Gräsbeck R., Lindblad B., Solberg H., WINKEL P. \& VIINIKKA L. (1993) Establishing reference values from adults: recommendation on procedures for the preparation of individuals, collection of blood, and handling and storage of specimens. Scand 7 Clin Lab Invest, 53, 649-652.

Arzt E., Sauer J., Pollmacher T., Labeur M., Holsboer F., Reul J. \& Stalla G. (1994) Glucocorticoids suppress interleukin-1 receptor antagonist synthesis following induction by endotoxin. Endocrinology, 134, 672-677.

Brenner I., Castellani J., Gabaree C., Young A., Zamecnik J., Shephard R. \& Shek P. (1999) Immune changes in humans during cold exposure: effects of prior heating and exercise. 7 Appl Physiol, 87, 699-710.

Connor T. \& LeOnard B. (1998) Depression, stress and immunological activation: the role of cytokines in depressive disorders. Life Sci, 62, 583-606.

De Rijk R., Petrides J., Deuster P., Gold P. \& SternBERG E. (1996) Changes in corticosteroid sensitivity of peripheral blood lymphocytes after strenous exercise in humans. 7 Clin Endocrinol Metab, 81, 228-235.

De Rijk R., Michelson D., Karp B., Petrides J., Galliven E., Deuster P., Paciotti G., Gold P. \& STERNBERG E. (1997) Exercise and circadian rhythminduced variations in plasma cortisol differentially regulate interleukin-1 beta, interleukin-6, and tumor necrosis 
factor alpha production in humans: high sensitivity of tumor necrosis factor alpha and resistance of interleukin6. 7 Clin Endocrinol Metab, 82, 2182-2191.

DhabHar F. \& McEven B. (1997) Acute stress enhances while chronic stress suppresses cell-mediated immunity in vivo: a potential role for leukocyte trafficking. Brain Behav Immun, 11, 286-306.

Dinan T. (1994) Glucocorticoids and the genesis of depressive illness. A psychobiological model. $\mathrm{Br} \mathcal{F}$ Psychiatr, 164, 365-371.

Dugué B., Leppänen E., Zhou H.-P. \& Gräsbeck R. (1992) Preanalytical factors and standardized specimen collection: influence of psychological stress. Scand 7 Clin Lab Invest, 52, 43-50.

Dugué B., Leppänen E., Teppo A.-M., Fyhrquist F. \& GRÄSBECK R. (1993) Effects of psychological stress on plasma interleukins-1 beta and 6, C-reactive protein, tumor necrosis factor alpha, antidiuretic hormone and serum cortisol. Scand 7 Clin Lab Invest, 53, 555-561.

Dugué B., Ilardo C., Aimone-Gastin I., Guéant J.-L., Mouzé-Amady M., Cnockaert J.-C., Mur J.-M. \& GRÄsBECK R. (1996a) Cytokines in saliva. Basal concentrations and the effect of high ambient heat (sauna). Stress Med, 12, 193-197.

Dugué B., Leppänen E. \& Gräsbeck R. (1996b) Preanalytical factors and the measurement of cytokines in human subjects. Int 7 Clin Lab Res, 26, 99-105.

Dugué B., Leppänen E. \& GRÄsbeck R. (1998) Effects of thermal stress (sauna + swimming in ice-cold water) in man on the blood concentration and production of pro-inflammatory cytokines and stress hormones. Pathophysiology, 5 (suppl 1), 149.

Dugué B., Leppänen E. \& Gräsbeck R. (1999) Preanalytical factors and the measurement of serum soluble intercellular adhesion molecule- 1 in man. Influence of the time of the day, food intake, psychological and physical stress. Clin Chem, 45, 1543-1547.

Fyhrquist F., Wallenius M. \& Hollemans H. (1976) Radioimmunoassay of vasopressin in unextracted plasma. Scand 7 Lab Clin Invest, 36, 841-847.

GaIllard R. (1994) Neuroendocrine-immune system interactions. The immune-hypothalamo-pituitary-adrenal axis. Trends in Endocrinology and Metabolism, 5, 303-309.

Jansky L., Pospisilova D., Honzova S., Ulicny B., Sramek P., Zeman V. \& Kaminkova J. (1996) Immune system of cold exposed an cold adapted humans. Eur f Appl Physiol, 72, 445-450.

Jezova D., Kvetnansky R. \& Vigas M. (1994) Sex differences in endocrine responses to hyperthermia in sauna. Acta Physiol Scand, 150, 293-298.

Kauppinen K. \& URPonen H. (1988) The winter swimmer's self portrait. Arctic Med Res, 47, 4-12.
Kauppinen K., Pajari-Backas M., Volin P. \& Vakkuri O. (1989) Some endocrine responses to sauna, shower and ice water immersion. Arct Med Res, 48, 131-139.

KJAER M. (1998) Adrenal medulla and exercise training. Eur J Appl Physiol, 77, 195-199.

Kukkonen-Harjula K., Oja P., Laustiola K., Vuori I., Jolkkonen J., Sittonen S. \& VapaAtalo H. (1989) Haemodynamic and hormonal responses to heat exposure in a Finnish sauna bath. Eur 7 Appl Physiol, 58, 543-550.

Kvernmo H., Olsen J. \& Osterud B. (1992) Changes in blood cell response following strenuous physical exercise. Eur 7 Appl Physiol, 64, 318-322.

Maes M., Bosmans E., De Jongh R., Kenis G., VandoOlaEghe E. \& NeEls H. (1997) Increased serum IL-6 and IL-1 receptor antagonist concentrations in major depression and treatment resistant depression. Cytokine, $\mathbf{9}$, 853-858.

Nerad J., Griffiths J., Van Der Meer J., Endres S., Poutsiaka D., Keusch G., Bennish M., Salam M., Dinarello C. \& CanNon J. (1992) Interleukin-1beta, IL-1 receptor antagonist, and TNF alpha production in whole blood. 7 Leukoc Biol, 52, 687-692.

Päth G., Bornstein S., Ehrhart-Bornstein M. \& Scherbaum W. (1997) Interleukin-6 and the interleukin-6 receptor in the human adrenal gland: expression and effects on steroidogenesis. 7 Clin Endocrinol Metab, 82, 2343-2349.

Rock C., Coyle S., Keogh C., Lazarus D., Hawes A., Leskiw M., Moldawer L., Stein T. \& Lowry S. (1992) Influence of hypercortisolemia on the acute-phase protein response to endotoxin in humans. Surgery, 112, 467-474.

Salas M., Evans S., Levell M. \& Whicher J. (1990) Interleukin-6 and ACTH act synergistically to stimulate the release of corticosterone from adrenal gland cells. Clin Exp Immunol, 79, 470-473.

SAPOLSKY R. (1993) Why Zebras Do Not Get Ulcers. Freeman Publishers, New York, USA.

Sauer J., Castren M., Hopfner U., Holsboer F., Stalla G. \& ARTZ E. (1996) Inhibition of lipopolysaccharideinduced monocyte interleukin-1 receptor antagonist synthesis by cortisol: involvement of the mineralocorticoid receptor. 7 Clin Endocrinol Metab, 81, 73-79.

Waage A., Slupphaug G. \& Shalaby R. (1990) Glucocorticoids inhibit the production of IL6 from monocytes, endothelial cells and fibroblasts. Eur 7 Immunol, 20, 2439-2443.

Weber M., Michl P., Auernhammer C. \& Engelhardt D. (1997) Interleukin-3 and interleukin-6 stimulate cortisol secretion from adult human adrenocorticol cells. Endocrinology, 138, 2207-2210.

Zenner R., De Decker D. \& Clement D. (1980) Bloodpressure response to swimming in ice-cold water. Lancet, i, 120-121. 